prevent any dragging upon the skin at these points. As the main portion of the threads lie over and at right angles to the line of union, they may be utilised for keeping in position the deeper dressing, which may be passed beneath them, but this is not an essential feature of the method.

\section{A CASE OF HODGKIN'S DISEASE.}

\section{By WILliaM E. L. ALLEN, M.B., C.M.Glas.,} Hawkshead, near Ambleside.

A. E., aged three years and a-half, previously healthy, with the exception of a mild attack of scarlet fever followed by measles in October, 1895, was first seen on March 7th, 1896. She was suffering from a scratch by a cat on the ring finger of the right hand, which was very much inflamed and suppurating. About a week later an abscess formed in the right axilla, which when opened discharged a dark brown offensive fluid, This healed under ordinary treatment, but was accompanied by some sloughing. About this time some glands below the left ear became slightly enlarged, but the swelling disappeared on painting with weak iodine liniment.

About the middle of April the cervical and submaxillary glands, axillary and inguinal glands were found to be swollen on both sides. Under iodide of potash internally and iodine externally there was considerable diminution in the size of the cervical glands on the right side, and subsequently slight improvement in those of the left side. None of the glands exceeded the size of an almond, many not being larger than a pea. It was impossible to count them, so many being involved, but all were freely movable-distinct and free from pain. The complexion became very waxy and there was marked leukæmia, the spleen was easily felt about an inch below the ribs, about the size of an orange. There was also considerable enlargement of the liver. The face and body were very much swollen, but there was no pitting on pressure and the swelling was more a puffiness than actual œdema. The bowels and kidneys acted freely. The temperature was slightly above normal, but never more than ${ }_{102}{ }^{\circ} \mathrm{F}$., shortly before death. At the beginning of May there was epistaxis, but not severe, though it continued more or less the whole of one day. There were very marked purpuric spots on the arms, legs and lower part of the body, the largest being about the size of a threepenny piece. On May 6 th pneumonia set in, which proved fatal on May roth. Four days before death there was suppuration from the right ear.

This case is interesting owing to the early age of the patient and to its rapid termination, as there was only a period of nine weeks from the first distinct appearance of the complaint-dating back to the first enlargement of the cervical glands-before death took place. It is also interesting on account of the suppuration from the ear, which in this case was a sequel of the complaint and not a cause of it as suggested by Trousseau. Though there is a history of a poisoned (?) wound, it can scarcely be looked upon as a case of septicæmia, but rather as the cause of the scratch taking on an unhealthy action, as the symptoms point conclusively in favour of Hodgkin's disease.

As to treatment, arsenic and phosphorus have been used, but without any marked benefit except in Billroth's case, where arsenic was used. In this case the glands diminished under pot. iodid., but that has been observed under other forms of treatment, shortly before death and apparently independent of treatment. In a future case I should be inclined to give the gland treatment a trial.

\section{A CASE OF HEAT STROKE : HYPERPYREXIA: RECOVERY.}

By GERALD SICKEL, Surgeon, R.N.

[Communicated by the DIREctor General, Medical Department, R.N.

THE following interesting case occurred on board H.M.S. Gibraltar after she had been in the Mediterranean just over a month :

On July I 3 th, when at Palma, in Majorca, at 6 P.M., J. W., an engine-room artificer, aged 27, came down to the sick-bay, complaining of headache and pains in the legs. His temperature was $100.4^{\circ}$, his tongue slightly furred, helooked pale and ill and was put in a cot in the sick-bay.

He lay there sleeping until 9 P.M. when the sick-bay steward thought he seemed slightly delirious and took his temperature which was 105.2 ${ }^{\circ}$, shortly afterwards his breathing became stertorous, and he lay comatose with a temperature $109.2{ }^{\circ}$ full rapid pulse, pale face, closed eyes, pupils equal and fixed about half-way between dilatation and contraction: his venous system was engorged, his body dry and felt burning hot: at times he groaned loudly and struggled to get out of bed.

He was bled to 6 oz., but it apparently did him no good, and his breathing becoming rather embarrassed he was given a hypodermic injection of 5 minims of liquor strychninæ; meanwhile a bath was being prepared, into which he was put, the temperature of the water being brought by ice from tepid to about $65^{\circ}$ in half an hour. This brought his temperature down to IOI.2 ${ }^{\circ}$, otherwise his condition remained unaltered. At II.30 P.M., he was given a large soap enema, which emptied the lower bowel of a greal deal of fæces, in part scybalous. Later his temperature rose to $103.4^{\circ}$, at 12.30 104. $6^{\circ}$ and he began to have epileptiform fits, in one of which he bit his tongue : later he had fits every 10 minutes.

At 2 A.M. on July inth the temperature was $107.8^{\circ} \mathrm{He}$ was put in a cold pack and his body rubbed with ice, the temperature came down, till at 5 A.M. it was normal, with pulse 104, respirations 22, he began to grow a little conscious and recognised being called by name. He was sick several times during the night. Later he became fairly conscious and his temperature did not go above $99^{\circ}$.

On July I 5 th the temperature kept down, but he was sick after every thing he ate; he had a very restless night; morphine gr. $\frac{1}{4}$, with atropine gr. $\frac{1}{5} \sigma^{\frac{1}{5} \sigma}$ did no good. Urine: acid, specific gravity 1024, no albumen.

July 16 th, the temperature was $99^{\circ}$ and the pulse 76 in the morning. Vomiting had ceased, but he was still very restless; he was not fully conscious but complained of diplopia and difficulty of hearing. Towards evening he became more and more restless and in the end he struggled so violently that he had to be tied down in bed. Morphine, gr. $\frac{1}{2}$, and bromide potassium $3 \mathrm{ss}$ did no good. During the ensuing night the temperature went up ro2.2 ${ }^{\circ}$ : and he was put in a wet pack.

On July I7th, at I.35 A.M. he was given 30 grs. of chloral hydrate, after which he had a sound sleep. After he woke his mind was wandering, and he passed urine under him twice, the tongue very dry and furred: with sordes in teeth and lips. He was given another dose (20 grains) of chloral, after which he slept all day, having to be waked to take his food (beef tea and eggs beaten up) which he kept down well. At 9 P.M. the temperature $99^{\circ} 2^{\circ}$ the pulse 68 and the respirations 20.

On July i8th, he had had a very good night, but required another 20 grains of chloral in the evening.

From this date he steadily improved until on the 22nd he was allowed to sit up for two hours in the evening.

Until July 19th, he had a decided impediment in his speech, sbut this then almost entirely disappeared-he had some slight peculiarity of speech before the stroke-and this of course remained. From this date onwards he made an uninterrupted recovery.

An ophthalmoscopic examination was made on July $23 \mathrm{rd}$, there was no optic neuritis, or atrophy, or retinitis.

Comments. - There was nothing very peculiar about the atmospheric conditions on the day of the stroke. The barometer at 4 P.M. was 30.12 in., thermometer $87^{\circ}$ in the shade and relative humidity (100-saturation) 52 : but we had just come from Malta, where everyone appeared to get "run down." The thermometer night or day hardly ever fell below $80^{\circ}$. From 7 A.M. until 3 P.M. he had been working in the engine-room where the temperature was $100^{\circ}$. About the same time that this man was ill, we had several minor cases of heat stroke, the majority of them among those who worked in the engineers' department.

It is interesting to notice that, as is so often the case, the stroke came on in the comparatively cool evening.

Sir Joseph Fayrer objects to bleeding in these cases as a rule, but in this man|the nervous system was so obviously engorged, 